\title{
Da excelência ao lixo: humilhação, assédio moral e sofrimento de trabalhadores em fábricas de calçados no Ceará
}

\author{
Izabel Cristina Ferreira Borsoi $^{\mathrm{I}, 1}$, Raquel Maria Rigotto ${ }^{\mathrm{II}, 2}$ e Regina Heloisa Maciel ${ }^{\mathrm{II}, 3}$ \\ ${ }^{1}$ Universidade Federal do Espírito Santo \\ ${ }^{\text {II }}$ Faculdade de Medicina da Universidade Federal do Ceará \\ III Universidade de Fortaleza e Universidade Estadual do Ceará
}

\begin{abstract}
Este artigo tem como objetivo discutir a vivência de humilhação e de sofrimento de trabalhadores da indústria calçadista com histórias de acidentes ou de adoecimento do trabalho, e também de competência e dedicação à empresa. É parte dos resultados da pesquisa "Violência e trabalho: acidentes de trabalho e humilhação na indústria calçadista do Ceará". A discussão fundamenta-se nos relatos de três trabalhadores de duas fábricas de calçados de grande porte instaladas no Ceará, selecionados entre 20 entrevistados com histórias de humilhação e constrangimento. Os resultados mostram que, no caso desses trabalhadores, a competência e a dedicação ao trabalho, resultantes da introjeção do ideal de excelência exigido nas empresas, levaram a uma maior exposição aos riscos presentes no ambiente de trabalho. Uma vez com a capacidade produtiva limitada, o trabalhador torna-se, então, alvo frequente de situações de humilhação e constrangimento - compondo um quadro de assédio moral. Essa vivência faz com que o trabalhador sinta-se traído, desprezado e descartado pela empresa, apesar de seu esforço e dedicação a ela. Isso tem sido apontado como um dos elementos importantes de intensificação do sofrimento físico e mental.
\end{abstract}

Palavras-chave: Assédio moral, Humilhação, Acidentes de trabalho, Trabalhador da indústria calçadista, Ideal de excelência.

From excellence to trash: humiliation, bullying and suffering amongst footwear industry workers in Ceará, Brazil

This article discusses humiliation and suffering experiences amongst footwear industry workers with histories of accidents or sickness related to work, but that also have a history of dedication and competence in relation to their enterprises. It is part of the results of a larger research dealing with "violence and work: accidents and humiliation in the footwear industry in Ceara State (Brazil)". The discussion is based on the discourse of three workers of two different footwear industries of Ceará State, selected from a pool of 20 interviewees with histories of humiliation and constraints. The results have shown that, in the case of these workers, competence and dedication to work, related to introjections of the excellence ideal, as it is reinforced today in the industries, led to a greater level of work environment risk exposure. Once their productive capacity shows some limitations, the worker is frequently victim of humiliations and constraints - resulting in work-related bullying. This kind of experience leads to feelings of betrayal, contempt and discard, despite the workers' effort and dedication to the enterprise. This can be one of the factors responsible for the intensification of mental and physical suffering in the work.

Keywords: Bullying, Humiliation, Work accidents, Footwear industry workers, Excellence ideal.

1 Psicóloga, mestre em psicologia social, doutora em sociologia e professora do Departamento de Ciências Sociais e do Programa de Pós-Graduação em Ciências Sociais da Universidade Federal do Espírito Santo.

2 Médica do trabalho, mestre em educação e doutora em sociologia. É professora do Departamento de Saúde Comunitária da Faculdade de Medicina da Universidade Federal do Ceará, coordenadora do Núcleo Tramas (Trabalho, Meio Ambiente e Saúde para a Sustentabilidade) e coordenadora da pesquisa na qual se fundamenta este trabalho.

3 Psicóloga, mestre em applied psychology ergonomics, doutora em psicologia (psicologia experimental) e professora da Universidade de Fortaleza e da Universidade Estadual do Ceará. 


\section{Introdução}

Situações de humilhação e de constrangimento no trabalho, atualmente denominadas de $\checkmark$ assédio moral, apenas recentemente começaram a ser reconhecidas como causadoras de impactos sobre a saúde física e mental dos trabalhadores (Maciel et al., 2007). Na definição do assédio moral no trabalho, destacam-se a ocorrência de atos negativos por parte das chefias ou colegas e a posição de vulnerabilidade da vítima, que não pode defender-se, o que implica a existência de um desequilíbrio típico das relações de poder (Einarsen, 2005). Outros aspectos importantes de tal definição são a continuidade e o caráter repetitivo das ações negativas perpetradas contra o trabalhador.

Os atos normalmente considerados negativos vão desde a falta de cortesia até a violência física, passando por gritos, xingamentos e atitudes e ações relacionadas diretamente ao trabalho, tais como pressão por produção, exigência de cumprimento de metas quase inatingíveis, retirada de responsabilidades, isolamento do trabalhador, dentre outros. Em geral, o objetivo do agressor é desestabilizar a vítima, expulsá-la do grupo ou da empresa ou, então, obter vantagens como facilidade de manipulação ou, simplesmente, poder.

As principais consequências do assédio são: depressão, ansiedade, sociofobia, ataques de pânico, baixa autoestima e desordens psicossomáticas, tais como insônia, melancolia, apatia, falta de concentração, sudorese, tremores e outros sintomas comportamentais (Bjorkqvist, 2001; Hansen et al., 2006; Hoel et al., 2001; Hoel et al., 2004; Matthiesen \& Einarsen, 2004; Tehrani, 2004).

É importante destacar que o assédio está fortemente associado às chamadas "novas formas de organização do trabalho", que incluem a utilização de determinados princípios toyotistas (Antunes, 2005) e cujo objetivo é levar os trabalhadores a sentirem-se comprometidos com as metas da organização e seu ideário. Ao tomar como suas as metas e os objetivos da empresa, o trabalhador assegura, de algum modo, o salário e o emprego. No entanto, as metas, às vezes, estão acima das capacidades técnicas da empresa e também das capacidades pessoais dos próprios trabalhadores.

A impossibilidade ou dificuldade em cumpri-las pode levar a uma verdadeira "neurose". A "neurose da excelência" é descrita por Aubert (2001) como aquela que decorre da "luta constante que mantemos para satisfazer os ideais de excelência que caracterizam nossa sociedade e que certas empresas encarnam com particular acuidade" (p. 187). Essa talvez seja a situação mais perniciosa de assédio moral, pois incita os trabalhadores a irem além de seus limites, violentando sua saúde e seu bem-estar.

Essas situações podem expor o trabalhador a maiores riscos de acidentes e adoecimento. Uma vez acidentado ou adoecido, passa a sofrer o assédio de modo mais explícito e transparente, porque ele já não condiz com os padrões de "excelência" e, portanto, "não serve mais" para a organização. A partir desse momento, começa seu processo de isolamento, não apenas pelas ações e atitudes das chefias, mas, também, pela omissão dos colegas que, por medo ou vergonha, acabam reproduzindo o clima de "terror" instalado. É o que Barreto (2002) chama de "pacto da tolerância e do silêncio no coletivo".

Este artigo tem como objetivo discutir esse tipo de problema e toma como base as vivências de humilhação e de sofrimento de trabalhadores de fábricas de calçados no Ceará que têm, em comum, histórias de acidentes ou de adoecimento ligados à atividade laboral, bem como de competência e dedicação à empresa. É parte dos resultados da pesquisa "Violência e 
trabalho: acidentes de trabalho e humilhação na indústria calçadista do Ceará” ${ }^{4}$, que se propôs analisar formas de violência caracterizadas como acidentes de trabalho e humilhação em três unidades fabris de duas empresas calçadistas de grande porte, oriundas da região Sul e instaladas no Ceará a partir de 1995.

A discussão apresentada a seguir está fundamentada em relatos de três trabalhadores de duas fábricas, que nomeamos "fábrica A" e "fábrica B". Francisca, trabalhadora da fábrica A, foi acometida por LER/DORT (Lesões por Esforços Repetitivos/Distúrbios Osteomusculares Relacionados ao Trabalho). Armando, trabalhador da fábrica B, sofreu esmagamento de um dedo da mão. Zizu, trabalhador também da fábrica $A$, teve ferimentos nas mãos que dificultavam seu trabalho, mas sequer deu-se conta de que se tratava de acidente de trabalho. Esses trabalhadores foram selecionados em um grupo de 20 entrevistados que relataram situações de humilhação. ${ }^{5}$ A escolha deu-se em razão da riqueza das informações que forneceram sobre o trabalho que realizavam, o envolvimento com a organização laboral, os danos físicos sofridos e as experiências de humilhação pelas quais tinham passado. Esses trabalhadores eram, então, paradigmáticos no conjunto dos entrevistados da pesquisa. Para evitar quaisquer constrangimentos ou riscos de punição nas fábricas, todos foram entrevistados em suas próprias residências, sendo localizados através da estratégia da "bola de neve". Assim, ao final de cada entrevista, era solicitado ao trabalhador que indicasse colegas que pudessem participar da pesquisa. Visando preservar suas identidades, todos foram convidados a sugerir um pseudônimo pelo qual fossem identificados tanto durante as entrevistas quanto neste artigo. Portanto, os nomes que aqui aparecem são fictícios.

A fábrica A produz tênis e calçados de couro. Está instalada na região metropolitana de Fortaleza desde 1995 e integra um conjunto de três fábricas de calçados femininos pertencentes a um grupo empresarial oriundo da região Sul. No final de dezembro de 2006, contava com cerca de 2.400 funcionários, sendo 1.483 do sexo feminino e 854 do sexo masculino. Produz em torno de 15.000 pares de calçados por dia. A gestão da produção é feita com base no modelo taylorista-fordista, mas envolve também um mix de elementos do toyotismo, como a especialização flexível, a definição de metas e o discurso da qualidade total.

A fábrica B produz calçados femininos. Foi instalada há 13 anos em um município próximo de Fortaleza, pertence a um grupo industrial também oriundo da região Sul e é a maior de um conjunto de quatro unidades localizadas no estado, respondendo por $80 \%$ de sua produção total no Ceará. No início de 2007, a fábrica contava com 16.365 empregados. Embora o processo de produção seja distinto da fábrica A, expondo os trabalhadores a maiores riscos de acidentes, em razão do tipo de material utilizado na fabricação, o modelo de gestão segue parâmetros similares em ambas as fábricas.

Cabe ressaltar que, desde o início dos anos 1990, o Ceará vem destacando-se como um estado atraente para investimentos de capital industrial, geralmente oriundos das regiões Sul e Sudeste. Sua política de incentivos fiscais, a presença de numerosa força de trabalho de baixo custo e a localização geográfica favorável, devido à existência de porto marítimo, são as principais bases dessa atração (Rigotto, 2007).

As empresas que migram para o estado buscam novos territórios - normalmente regiões pouco industrializadas - para expandir sua produção, integrando, assim, o contexto de

4 Pesquisa coordenada por Raquel Maria Rigotto, realizada com financiamento do CNPq (Conselho Nacional de Desenvolvimento Científico e Tecnológico) e concluída em novembro de 2007, conforme relatório elaborado com a participação de Regina Heloisa Maciel, Izabel Cristina Ferreira Borsoi e outros colaboradores.

5 Além das entrevistas mencionadas acima, a pesquisa na qual este artigo está fundamentado partiu da análise do processo de trabalho das três unidades fabris, através de observação direta da produção de uma dessas unidades e de entrevistas com ocupantes de cargo de gerência; da descrição e análise do perfil dos acidentes de trabalho com trabalhadores dessas indústrias, oficialmente registrados no período de 2000 a 2005 e cujos dados foram acessados através da Previdência Social; da caracterização aprofundada de diversos aspectos dos acidentes registrados em 2006, tomando como referência as Comunicações de Acidentes de Trabalho (CATs) e as informações obtidas mediante entrevistas estruturadas, envolvendo ao todo 134 trabalhadores, vítimas de acidentes nessas fábricas. 
acirramento da globalização dos mercados mundiais e de ampliação e intensificação da concorrência nos mercados interno e externo, observado nas duas últimas décadas (Francischini \& Azevedo, 2003; Navarro, 2006; Prochnik \& Une, 2005). Em geral, suas plantas produtivas requerem grandes contingentes de trabalhadores para ocuparem postos de trabalho pouco qualificados e caracterizados por atividades simplificadas e repetitivas, como ocorre nas fábricas de calçados, locais onde podemos encontrar trabalhadores vivendo situações como as que apresentamos neste artigo.

\section{A história de Francisca: da excelência ao lixo}

Francisca, 36 anos, casada, trabalha há dez anos na fábrica A, sempre como costureira, permanecendo em pé durante toda a jornada. $\mathrm{O}$ movimento de pegar e repassar as peças na esteira e colocá-las e retirá-las da máquina era realizado sempre com o braço suspenso a uma altura maior do que a da própria máquina, já considerada muito alta.

Apesar de sua inexperiência industrial anterior, Francisca aprendeu com facilidade as tarefas e as assumiu como suas, alcançando, assim, as metas definidas pela empresa. Sua excelência era reconhecida pelas chefias, chegando a ser disputada entre os gerentes e "emprestada" para outras fábricas para "desafogar" a produção.

Francisca relata que, há cerca dois anos, começou a sentir dor leve no braço esquerdo, próximo ao ombro, mas não julgou o fato importante. A dor intensificou-se aos poucos e, mesmo tornando-se significativa, não fez com que procurasse ajuda médica. A identificação com as metas da empresa, provavelmente, levava Francisca a subestimar os sinais que o corpo lhe dava, indicando seus limites, e a postergar atitudes de autodefesa. Essa postura é frequente em trabalhadores, que, muitas vezes, são obrigados, a partir de então, a conviver com a dor ao longo de sua vida.

À medida que os sintomas se agravavam, já comprometendo sua produtividade, Francisca recorria aos profissionais de saúde da empresa, mas recebia somente injeções para combater a dor e era enviada de volta ao trabalho. Suas queixas eram sistematicamente desconsideradas ou subestimadas pelos profissionais do serviço médico.

Seu problema foi reconhecido somente quando procurou o médico do plano de saúde do marido. Francisca relata que, além da dor que limitava sua capacidade de trabalho, seu braço também já apresentava outro sintoma: inchaço. A primeira licença médica deu início a uma verdadeira via crucis na busca do reconhecimento da doença e dos direitos de acidentada. É exatamente nesse momento que começa sua história de humilhações decorrentes das limitações causadas pela LER/DORT.

Embora o afastamento de qualquer atividade que envolva esforços repetitivos seja imperioso no tratamento desses casos - e, normalmente, tais afastamentos são prolongados -, no último ano (2007) Francisca teve somente três licenças de quinze dias, concedidas pelo médico particular, e uma que durou dois meses. Esta última lhe garantiu auxílio-doença do INSS (Instituto Nacional de Seguridade Social), que, entretanto, não reconheceu o nexo entre o adoecimento e o trabalho. A empresa, por seu turno, também não o fez e, sendo assim, não emitiu a Comunicação de Acidente de Trabalho (CAT), muito provavelmente porque isso poderia levá-la a ter que reconhecer as inadequadas condições laborais.

Francisca conta que um dos gerentes principais reconheceu a gravidade do problema e sua impossibilidade de permanecer como costureira, admitindo que a doença devia-se ao trabalho na fábrica. Apesar disso, negou-se a emitir uma CAT, dificultando, desse modo, o acesso da trabalhadora aos benefícios a que teria direito durante o período de afastamento, bem 
como à estabilidade no emprego por um ano após a alta dada pelo INSS. O que lhe foi oferecido, ao contrário, iria deixá-la ainda mais desamparada e à mercê da própria sorte. Segundo ela, o que ouviu do gerente foi:

"É... pois então, você que dê um jeitinho de ficar por aqui, né? Emprego fora você não arranja mais, né?, desse jeito. Aí tu pegou aqui, né?". Eu disse: "Foi". "É, então, se quiser sair a gente dá um jeitinho e te tira, mas emprego fora você não arranja ...".

Esse diálogo, por si só, já pode ser considerado assédio moral, uma vez que um dos atos negativos perpetrados por empresas contra os trabalhadores é a "pressão para não reivindicar seus direitos" (Maciel et al., 2007), evitando, assim, ter que se haver com problemas jurídicos. A consequência disso é a intensificação do sofrimento do trabalhador, pois se somam a dor física, a mágoa, o sentimento de desamparo e o medo de não mais poder trabalhar. É o que revela Francisca:

E eu gostava, mulher, de trabalhar lá. Gostava do serviço que eu fazia. Eu era uma costureira profissional mesmo, me garantia. Ave Maria! Eles davam o maior valor a mim. Depois que eu adoeci, minha amiga, perdi o valor: é só aguentando humilhação. E quando foi em novembro, que eu me afastei, eu cheguei pra o gerente (que tem que levar pra o gerente ver). Aí, ele foi, pegou o meu crachá, o papel que eu trouxe, pegou o cara lá da cronometragem: "Tá aqui , pegue ela, faça qualquer coisa dela, jogue ela onde quiser, que aqui na minha fábrica eu não quero não" [...]. Ah, mulher! Nesse dia foi o mesmo que ele ter me pegado, assim, e me dado uma pisa, porque, quando eu... eu me lembrei do meu passado, porque, mulher... eu, lá dentro, não tinha ninguém que me tirasse da minha máquina pra me emprestar pra outra fábrica, não, porque de tão boa que eu era. Eu me orgulhava de tá lá dentro, mas, ultimamente, minha amiga, eu estou assim, como... com licença da palavra... uma cachorra lá dentro.

A história de Francisca vai construindo-se assim: de um lado, a imposição das metas de produtividade da empresa, a introjeção dessas metas como suas e o enorme esforço para cumpri-las; de outro, o adoecimento progressivo, a negação da doença por ela e pela empresa, até que uma situação-limite instala-se. Sentindo-se agora "inutilizada, acabada", Francisca entra em conflito com a empresa, que, antes, era sua grande referência. Nesse momento, a forma pela qual suas queixas são recebidas e pela qual ela é tratada - "uma cachorra" - leva-a a descobrir que só tinha valor enquanto era produtiva. Isso, segundo a entrevistada, "dói mais do que a dor" da própria LER.

Aos esforços repetitivos que ela não consegue mais fazer, somam-se, agora, os atos negativos repetitivos que a desestabilizam e a levam a desejar a demissão. Mas nem isso lhe é cedido. Depois da sessão de fisioterapia, Francisca vai para a empresa, bate o cartão e começa a andar de um canto a outro, sem posto de trabalho, sem função, sem lugar, sem valor.

Como a empresa não tem assumido as despesas de seu tratamento médico, Francisca arca sozinha também com os medicamentos, as passagens de ônibus para a fisioterapia e as consultas: "A empresa não está nem aí pra mim". Sequer o sindicato faz conta do que lhe acontece. Organizado por iniciativa da própria empresa, a direção sindical age como se a entidade fosse uma extensão da fábrica. Entrevistado em outro estudo, seu então presidente referia-se às queixas das trabalhadoras com LER como "essas besteiras dessas moças", reforçando a postura de negação existente por parte da empresa (Rigotto, 2004). Daí que a direção do sindicato também não tenha procurado emitir a CAT nem tomado qualquer providência em relação ao tratamento da trabalhadora. Apenas dispõe-se aos encaminhamentos burocráticos em caso de demissão.

Com LER e assediada, Francisca agora precisa lidar, também, com a incompreensão de alguns colegas, que, segundo ela, não entendem a razão pela qual não tem mais atribuição ou tarefa específica do mesmo modo que eles. Ela, por seu turno, prefere ocultar seu problema por 
medo de que achem que tenha alguma outra doença. Por falta de informação, raramente menciona com clareza seu diagnóstico - a LER - e tem receio de que possa ter câncer: " $a$ doença".

Francisca fala de seus medos e de suas limitações, que também atingem seus afazeres domésticos e cuidados pessoais. Receia que possa ficar "aleijada" e ficar impossibilitada de cuidar da casa, de si e da família. Ao falar disso, chora.

E cada dia que passa está afetando mais meu problema. Eu estou vendo de uma hora pra outra eu ficar aleijada, sem movimento nesse braço, e o médico disse que é perigoso porque é desse lado [mostra o braço esquerdo], né? Também eu acho melhor ser desse [aponta o braço direito], porque desse... porque quando eu estou em crise eu não posso fazer nada. Pra pentear o cabelo é ruim, pra trocar de roupa é ruim, tudo é.

De certo modo, já se sente "aleijada". Por isso, usa roupas com mangas tentando ocultar o braço esquerdo, já com hipotrofia facilmente visível se comparado ao direito. O comprometimento de sua autoimagem e de sua autoestima, somado ao assédio vivido na fábrica, pode estar na base das queixas de insônia e de depressão às quais se refere Francisca.

Apesar de todos os empecilhos que tem encontrado durante o período de seu adoecimento, ela mostra-se sempre inconformada, destemida e determinada. Em que pese sua insistência em tomar providências, quando da entrevista, ela estava afastada do trabalho por atestado do médico do plano de saúde do marido, mas sem qualquer menção à doença relacionada ao trabalho. Por razões éticas, foi, então, orientada a procurar o Centro de Referência em Saúde do Trabalhador (CEREST/SUS) em Fortaleza, para os procedimentos adequados relativos ao tratamento e à Previdência Social.

\section{A história de Armando: de "máquina" humana a sucata}

Armando, 23 anos, casado, trabalha há três anos na fábrica B, no setor de pintura, como operador de matriz e "soltando bandeirinha". Sofreu um acidente em uma máquina de lavar formas que lhe "esmagou" um dedo. Foi atendido na Santa Casa, onde passou por uma cirurgia. Afirma que perdeu o tato e a força da mão. Estava cumprindo o tempo de estabilidade após o retorno do tratamento, o que deveria terminar no início de 2008. Julgava que seria demitido após esse período.

Seu trabalho era pegar formas sujas de tinta na esteira, colocá-las numa máquina a ar comprimido, na qual são lavadas com acetona. Ao depositar as formas, a máquina fecha-se. Ao retirá-las, a limpeza é completada com um pano. Essa atividade é feita em ritmo acelerado, pois as formas precisam ser postas "na esteira de novo para rodar". Os EPIs (Equipamentos de Proteção Individual) usados nessa tarefa consistem somente em luvas e óculos. Armando fala, com amargura, sobre o acidente e sobre sua condição de acidentado na fábrica.

Avalia que a causa do seu acidente foi a intensa cobrança de produção. Com isso, pode-se inferir que sua necessidade de cumprimento de metas, de manter-se dentro dos padrões de excelência produtiva da empresa, somada às condições específicas de sua atividade e da própria máquina, levou-o ao acidente. Não se trata de desatenção ou negligência, mas de submissão à pressão das chefias. Por um lado, teme ser demitido, mas, por outro, parece introjetar a necessidade da empresa de atender à demanda de seus clientes, sentindo-se, então, na obrigação de dedicar-se ao máximo.

Ora, uma empresa na qual os trabalhadores precisam adequar-se às suas exigências por medo e não têm lugar para expressar suas ideias não pode, também, esperar bons resultados em 
termos produtivos (Ausfelder, 2002). Não pode, igualmente, esperar bons resultados em relação à integridade física e mental dos trabalhadores.

Depois do acidente, Armando afirmou que o médico da empresa não fez caso de sua queixa. Pelo que informa, continuou trabalhando durante um ano, aproximadamente, apesar da dor que sentia no dedo. Naquele período, chegou a ter atendimento médico fora da fábrica, mas sem que isso resolvesse seu problema. Chegou, mesmo, a pensar em pedir demissão. Relatou um intenso sofrimento durante aquele período: "Não dormia à noite porque o dedo doía. Às três horas da manhã, acordava [com o dedo] latejando, não tinha solução. A empresa não respondia nada. Tive crise de choro. Aí fui me tratar com um psicólogo".

Se o trabalhador não vê saída para sua situação de sofrimento, passa a lidar com o sentimento de desamparo. É o que, não raramente, enfrentam os trabalhadores quando não conseguem diagnósticos conclusivos ou reconhecimento dos agravos sofridos no trabalho. Desacreditados pelos médicos, pelas gerências das empresas e, muitas vezes, também pelos profissionais que os atendem no serviço público de saúde, em razão do despreparo para casos como esses; sem poder contar com apoio dos sindicatos, que, às vezes, estão atrelados à empresa; sem recursos financeiros para buscar atendimento especializado - em um quadro como esse, os trabalhadores, além da dor física, enfrentam o intenso sofrimento psíquico diante de sua própria impotência.

Armando, por fim, procurou atendimento na Santa Casa do município, onde um médico o encaminhou para cirurgia e recomendou que tomasse providências em relação à empresa, já que seu caso tinha sido negligenciado.

[...] não vou negar que a empresa me ajudou na época que em eu precisei de um apoio no emprego. Mas, aí, o que eu acho da fábrica B é que, no meu acidente de trabalho, eu estou com sequelas do acidente, ela não me deu apoio suficiente... a negligência dela. Depois de um ano, eu tive que fazer uma cirurgia. Aí, esperei essa cirurgia e, depois dessa cirurgia, fiquei defeituoso do dedo, aleijado. Praticamente aleijado do dedo.

Diante da sequela do acidente, Armando passou, então, a responsabilizar a empresa pela perda de parte de sua capacidade produtiva. Teve seu acidente reconhecido e, nessa condição, conseguiu o direito à estabilidade por um ano. Mas, agora, considera-se "aleijado". Fala repetidamente da perda que resultou em limitação, em "ineficiência" para o trabalho enfim, em incapacidade para a manutenção de sua sobrevivência e a de sua família.

Olha, uns anos atrás aqui eu era perfeito e hoje eu estou com defeito. Tudo bem, é um dedo. O pessoal fala muito, já ouvi muitos dizer: "Rapaz, tu ficou aleijado de um dedo, não foi de um braço, de uma perna". Eu sei. Mas, aí, eu sinto essa ineficiência minha. Eu precisava desse dedo, eu perdi a força da mão e, aí, eu fico muito desmo... eu chego na empresa pra trabalhar e não tenho motivação, eu tô... Eu fiquei magoado com a empresa, certo? O modo de dizer, decepcionado com a empresa, eu fico angustiado ali dentro daquela empresa, sabendo que eu fiquei aleijado ali dentro e não tive apoio de ninguém.

Armando fala de seu "defeito", cansaço, deslocamento, desmotivação, decepção, mágoa, angústia e desesperança. Antes, já havia falado de depressão, perda de apetite e dificuldades de sono. Um conjunto de sentimentos e de sintomas que revelam uma vivência traumática e, também, sua impotência diante de uma situação para a qual não encontra solução.

Com as limitações que tem, permanece na fábrica sem uma função definida, pois encontra dificuldades para realizar as tarefas, dada a perda de força e de tato na mão, razão pela qual afirma que, ao fim da jornada, "eu dou graças a Deus que acabou o horário de trabalho pra voltar pra casa".

Hoje, eu, na fábrica... eu não faço quase nada. Ninguém me cobra, eu só bato o crachá. Não 
faço uma função. Estou na fábrica e passa supervisor, passa chefe e eles não falam comigo, como se dissesse assim: "Deixa passar o tempo que vai passar o dia dele de botar pra fora". Não sou cobrado, eu não faço nada na empresa.

Limitado pelo acidente, incapaz de trabalhar de acordo com as exigências da fábrica, Armando sente-se peça descartada da engrenagem de produção, máquina defeituosa, sem serventia; vê-se como um não-trabalhador, apesar de empregado e de realizar pequenas tarefas inventadas apenas para se ocupar. Tem consciência do sentido que tem sua força de trabalho para a empresa depois do acidente. E diz:

[...] a gente é como uma máquina pra eles [gerentes]. Se a gente não dá produção, descarta. Se a gente se machuca, deixa... descarta também. A gente não significa nada pra eles. Somos uma máquina pra trabalhar, porque tem várias lá fora para repor. Sai um, entra dez. Sai um, entra dez.

Armando tem clareza de que trabalhador, como força de trabalho, é "máquina", mercadoria abundante no mercado - portanto, facilmente substituível, descartável. De certo modo, sabe que o que se estabelece entre ele e o comprador de sua força de trabalho são "relações reificadas entre as pessoas e relações sociais entre as coisas" (Marx, 1983, p. 71). Por esse prisma, não é, então, o trabalhador que adoece ou acidenta-se, mas apenas a máquina que se quebra e deixa de funcionar.

Além de lidar com a instabilidade do emprego, pois sabe que será demitido, e com medo de não encontrar outro trabalho (o que é bastante provável, considerando sua qualificação e a limitação de sua força de trabalho), Armando ainda precisa haver-se com o contínuo descrédito dos profissionais do serviço médico da empresa:

[...] eu cansei do meu dedo estar inchado e pedir autorização ao supervisor pra ir à enfermaria. Nesse mês, mesmo, antes de eu ficar de férias, meu dedo estava doendo e eu fui me consultar com um médico. O médico pegou, foi embora e disse que não ia me atender: pegou, virou as costas pra mim e foi embora. Aí, eu tive que falar com a gerência pra chamar a atenção do médico. [...] A gente é muito humilhado lá dentro por médico, por funcionário, por todo canto.

Conta que essas atitudes de descaso são comuns em relação às queixas dos trabalhadores, parecendo, assim, tratar-se de uma prática generalizada na empresa. Provavelmente, para os profissionais do serviço médico, o trabalhador adoentado é apenas mais um queixoso que não está disposto ao trabalho. ${ }^{6}$

Armando não consegue ver formas de enfrentar a discriminação e a humilhação que sofre e a que assiste na fábrica. Ele, como seus colegas, sente-se vítima indefesa à mercê dos desmandos daqueles que ocupam função de mando. Seu sentimento de impotência e desamparo faz-se claro quando afirma: "A gente se sente muito discriminado, sem apoio" sequer do sindicato que o representa (ou deveria representá-lo).

Atualmente, Armando não consegue vislumbrar seu futuro de trabalho, seja na fábrica, seja fora dela. Diz que seu plano de vida laboral foi destruído pelo acidente, pela fábrica. Sente também sua vida pessoal comprometida, pois não consegue imaginar construir sua família na ausência de sua capacidade de trabalho. Tem consciência de que o mundo do trabalho, no capitalismo, é para os saudáveis e os mais aptos. E julga não ser mais esse o seu caso. Antes, havia a expectativa "de crescer na empresa, de fazer o máximo possível pra valorizar a empresa onde me empregou, pra um dia eu crescer na empresa e - quem sabe? - se tornar um supervisor". Agora, entretanto, as perspectivas são sombrias.

6 Os episódios de ameaça e de assédio não se restringem aos trabalhadores adoentados, acidentados ou com alguma forma de limitação física. Segundo relata Armando, isso pode ocorrer com qualquer um e por algo de pouca importância. 
Eu não tenho confiança mais na empresa onde eu trabalho porque, sem estar deficiente físico... assim... deficiente de uma coisa, já é difícil emprego, imagina uma pessoa que está... está... num emprego e depois sai deficiente depois de um ano. Não tenho mais planos pra empresa.

Apesar da decepção, da mágoa, da consciência de sua limitação e da ausência de planos, Armando acalenta o sonho de trabalhar fora da fábrica em alguma atividade diferente da que faz.

\title{
A história de Zizu: o choro e a resistência
}

Zizu, 22 anos, solteiro, trabalha na fábrica A há mais de quatro anos - primeiro, como montador e, por último, como riscador ${ }^{7}$ Entrou por intermédio da tia que lá trabalhava fazia algum tempo. Durante seu período de experiência, Zizu sofreu ferimentos nas mãos por não estar acostumado ao equipamento de trabalho, mas não procurou atendimento médico, porque não os considerou significativos. Conta que sofreu humilhação mais de uma vez e nomeia seu "algoz": um gerente oriundo do sul que era "ignorante". A primeira vez em que isso aconteceu foi ainda durante seu treinamento, deixando claro que os novatos estão mais expostos a situações como essa. Seu relato sobre os dois primeiros meses de trabalho é reproduzido aqui entrecortado, apenas com intervenções pontuais da entrevistadora.

\begin{abstract}
O gerente... eu mal tava dando conta [do trabalho]... o gerente queria porque queria que eu desse conta. Derramei lágrima dos olhos, mas não foi por chorar mesmo. Foi por chorar de raiva, porque eu não sabia fazer aquilo e ele queria que eu desse conta. Aí, disse a ele que eu não dava conta. Aí, ficou ameaçando, dizendo que ia botar eu pra fora. Aí, foi o jeito eu ficar mesmo. Aí, fiquei. Até minha mão abriu, sabe? [Como assim?] O calo abriu, saiu sangue nos cantos. [Por quê?] Por causa de [eu ter] forçando, não sabia fazer aquilo ali, sabe? Aí, eu tava me dando demais - sabe? -, que eu não sabia. Aí, os outros veteranos acostumados, já sabem como é o ritmo. A pessoa novata, não. A pessoa novata vai ali naquela pressão do gerente, ali, em cima direto. A pessoa fica com medo - né? -, fica nervoso. Passei um bom tempo assim. [Quanto tempo você ficou nessa situação?] Eu passei... eu acho que foi uns dois meses. [Você tinha quanto tempo de trabalho quando você começou a passar por isso?] Tinha nem... não tinha nem quinze dias de trabalho, não. Quando eu comecei, com dez dias de trabalho ele me colocou nesse serviço. Eu não sabia dar conta e ele queria porque queria que eu desse conta. O pessoal tudo olhando pra mim chorando. Pense que ele ia me humilhar! Não me humilhava, não. Eu só chorei de raiva, mesmo, porque eu não estava dando conta do serviço. Até os meus colegas já estavam dizendo: "Zizu, não fica assim não, que é assim mesmo". Aí, não, a pessoa está humilhando desse jeito a pessoa, sem saber. Pra mim, o gerente tinha que primeiro saber ouvir o seu funcionário. Eles não gostam de ouvir muito. É assim [que acontecem] as coisas lá.
\end{abstract}

Evidenciam-se, na fala de Zizu, a atitude autoritária da gerência e o descaso com a inexperiência do trabalhador e com a necessidade de treinamento adequado, mesmo para funções consideradas simples. Em geral, os treinamentos têm curtíssima duração e consistem em acompanhar o trabalho de um colega mais experiente, sem que haja preocupação efetiva com a segurança do trabalhador. O que parece importar é a produção, independentemente de quais sejam as características e as condições da atividade e a habilidade do trabalhador.

Zizu fala da raiva, do nervosismo e do choro diante dos colegas. Raiva e nervosismo por não dominar a tarefa, mas também pela exigência feita a si mesmo, de ter que saber para não perder o emprego. Choro como resposta-limite ao que se tornou insuportável: a dor física, o não-saber, a ameaça, o assédio. Entretanto, parece que o sentimento de ser constrangido e

7 O riscador marca o bico do tênis para delimitar onde deve ser passada a cola que vai prender, corretamente a ele, uma outra parte do calçado. 
humilhado sobressai-se à dor dos ferimentos. Perguntado sobre se havia buscado atendimento na empresa para cuidar das feridas, Zizu responde:

Não, só em casa mesmo. Os próprios meninos que trabalhavam comigo me diziam pra eu fazer as coisas em casa, pegar água com sal e colocar a mão, que a mão fica muito "encaliçada", às vezes, e rasga. A pessoa colocando [água com sal] fica melhor. [E você conseguia trabalhar com a mão desse jeito, ainda?] Conseguia não. Aí, teve um tempo que eu não consegui. Aí, eles viram que não estava dando mesmo. Aí, colocou outra pessoa. O auxiliar que estava me ensinando, aí colocou [outra pessoa]. Aí, com o tempo... aí, com o tempo, eu me garanti lá no serviço.

Zizu nem se dá conta de que os calos que sangravam resultavam de acidente provocado pelas características do material sobre o qual trabalhava, pelo modo inadequado de realizar o procedimento, pela pressão sobre sua produtividade e pela ameaça de ser mandado embora. Para ele, as dificuldades do seu trabalho dão-se apenas porque

O couro, ele é muito grosso - sabe? -, e as costuras são muito pontudas. Aí, a pessoa se machuca, devido o torno também [...] machuca no torno, quando o torno quebra. [...] E quando o torno quebra, a pessoa fere o braço. Os meus colegas tudinho, que trabalham com torno, só ferem mais é aqui, olhe, no cotovelo [Fala do cotovelo, mas aponta o punho]. É no punho, a pessoa vai, quebra, fura aqui.

Zizu assume seu acidente (que, para ele, não é acidente) como um problema pessoal e seus colegas, como um acontecimento comum, corriqueiro, que nem sempre carece de cuidado médico. Considera que seu trabalho não é "muito pesado, não; ele é ruim". Ao ser perguntado sobre se sofreu algum acidente, responde simplesmente: "Não, não sofri nenhum acidente, não". E justifica: "É porque eu presto muita atenção - sabe? - no serviço que eu faço. Quando eu vou fazer aquele serviço, eu olho o que vai acontecer, ai eu evito".

Todos parecem estar acostumados aos pequenos acidentes, que são percebidos como se fossem integrados à natureza do trabalho que realizam ou, mesmo, à condição "natural" de um indivíduo já habituado à precariedade do modo de viver e de trabalhar. Afinal, o que são calos, mesmo quando se rompem e sangram? O que são os arranhões? São apenas fatalidades! Afinal, muitas vezes, a preservação do emprego está em "ter que aguentar" o trabalho "enjoento", puxado, pesado (Borsoi, 2005a), em ter que se adaptar às tarefas e aos seus ritmos, apesar das adversidades. Como diz Zizu: "É só força de vontade, mesmo. Aí, fui me acostumando, me acostumando". Como seus colegas, ele sequer cogita que as condições laborais são inadequadas, que as metas de produção são elevadas, que a pressão das chefias é excessiva e, que, por fim, esse conjunto de elementos oferece riscos à sua integridade física e mental.

A percepção do acidente de trabalho como fatalidade só favorece as empresas, que, via de regra, responsabilizam os trabalhadores pelos agravos que sofrem, desincumbindo-se, assim, da responsabilidade de garantir a segurança no trabalho por meio de medidas efetivas que alterem as condições objetivas para sua realização (Borsoi, 2005b). De acordo com esse princípio, a causa do acidente é o "ato inseguro", resultado dos comportamentos inadequados dos trabalhadores, de sua inobservância das normas de segurança prescritas (Vilela et al., 2004). Em outras palavras, o acidente seria consequência da desatenção, da negligência e da teimosia do trabalhador. ${ }^{8}$

Destemido, determinado e autoconfiante, Zizu, quando pode, resiste às tentativas de constrangimento por parte de seus supervisores. Mas, a julgar pelo que relata, essa forma de comportamento não é muito comum entre os trabalhadores "novatos", que, segundo ele, são, juntamente com as mulheres, os que mais sofrem. 
Os considerados "veteranos", por seu turno, já calejados no trabalho puxado e acostumados à pressão, provavelmente conseguiram incorporar as agressões e as metas e aprender algumas formas de enfrentamento de tais situações. É o caso de Zizu, que, agora mais experiente, já não se deixa humilhar e vitimar-se pelo assédio e pode solidarizar-se com os colegas ainda inexperientes tanto para o trabalho, como para as situações de constrangimento, comuns na fábrica.

Em que pesem todas as situações em que foi constrangido por suas chefias, Zizu relata que nunca foram-lhe dirigidas palavras ou expressões que o desqualificassem, mas afirma que isso ocorria com colegas. Curiosamente, ele não considera que as ameaças em público e a pressão excessiva do gerente, a ponto de fazerem-no chorar, possam ser consideradas humilhações. Isso porque, para ele, humilhação é apenas ser xingado, desqualificado.

Não, não, não me xingou, nem nada, não. Só ficou só com aquelas palavras, aquelas palavras pesadas, mesmo, que ia me botar pra fora. Só assim, que ia me botar pra fora, que ia guardar minha ficha no DP [Departamento de Pessoal]. É assim, foi desse jeito. Só essas palavras, mesmo, mas xingar, nunca xingou, não. Nunca me humilhou.

Com a mudança da gerência da fábrica, Zizu diz que houve redução das tensões no trabalho, o que tornou a jornada "alegre". A raiva e o estresse dissiparam-se, apesar de não ter havido qualquer mudança objetiva nas condições físicas e nas tarefas no trabalho.

Sem questionar a baixa qualidade de seu posto, o salário que recebe ou, mesmo, a política de gestão da empresa, Zizu restringe sua crítica ao controle e à pressão exercidos pela gerência. Para ele, o problema resolver-se-ia se as chefias ouvissem e respeitassem os trabalhadores, pois, se não fossem as chefias "ignorantes", "a fábrica A era uma maravilha".

Ele espera poder trabalhar fora da fábrica, pois esta, para ele (como para grande parte de seus colegas), representa apenas um emprego transitório. A expectativa é de que encontre um trabalho mais gratificante e que valorize a capacidade que tem.

\section{Onde as histórias encontram-se: dor, humilhação, medo e desamparo}

Os três trabalhadores cujas histórias apresentamos aqui têm, em comum, o trabalho na indústria calçadista e, também, suas trajetórias de sofrimento. Na base desse sofrimento estão o adoecimento, o acidente de trabalho, as humilhações e os constrangimentos.

Francisca foi acometida por LER/DORT e ainda não teve sua doença reconhecida como relacionada ao trabalho. Armando sofreu um acidente que lhe esmagou um dedo e conseguiu garantir direitos básicos na condição de acidentado. Zizu teve suas mãos feridas em decorrência das características do material trabalhado e de sua inexperiência na atividade. Francisca e Armando insistem, de forma solitária, na busca de seus direitos como trabalhadores que já não estão capazes para trabalhar do modo como exigem as fábricas. Negam-se a aceitar ser condenados ao não-trabalho ou ao desemprego; negam-se a aceitar que sua força de trabalho já não tenha serventia nas fábricas.

Diferentemente de Francisca e Armando, Zizu sequer considerou seus ferimentos como resultantes de acidentes de trabalho, embora compartilhe com seus companheiros de infortúnio o sentimento de que também pode ser peça descartável a qualquer momento. Recuperado de seus ferimentos, sabe que, como qualquer um, não será apenas sua condição saudável que o manterá empregado. É preciso que produza de acordo com as exigências e com as metas impostas de cima para baixo. E isso ele faz com competência. 
Agora, Francisca e Armando estão incapacitados para o trabalho. Entretanto, como Zizu, também já experimentaram uma espécie de "síndrome de excelência" e "davam-se" ao máximo para satisfazer os ideais de excelência que as empresas tentam incutir nos trabalhadores. Em troca, foram "brindados" com um minguado salário, alguns benefícios, muita exigência, cobrança, doenças, acidentes, constrangimentos e humilhações. Mesmo assim, guardam em comum com Zizu o orgulho de terem sido produtivos, competentes e de sempre perseguirem as metas da empresa, fazendo-as suas. Uma atitude apropriada aos novos tempos, em que predomina a busca frenética pela qualidade, pela excelência e pelas gratificações imediatas, gerando ansiedade entre os trabalhadores por receio de não alcançarem as metas traçadas, como mostra Sennett (2006).

Dejours (1999) afirma que, em razão da mecanização e da robotização do trabalho, há os que insistem em fazer-nos acreditar que o sofrimento na esfera laboral foi atenuado ou, até, eliminado. Entretanto, em acordo com Sennett, argumenta que

[...] por trás das vitrinas, há o sofrimento dos que temem não satisfazer, não estar à altura das imposições da organização do trabalho: imposições de horário, de ritmo, de formação, de informação, de aprendizagem, de nível de instrução e de diploma, de experiência, de rapidez de aquisição de conhecimentos teóricos e práticos (Dessors \& Torrente, 1996) e de adaptação à "cultura" ou à ideologia da empresa, às exigências do mercado, às relações com os clientes, os particulares ou o público etc. (p. 28).

Disso conclui-se que, na corrida pelo reconhecimento da competência, e trabalhando sob pressão e em condições inadequadas, os trabalhadores estão cada vez mais expostos aos riscos de agravos, sejam eles acidentes, doenças ou transtornos psíquicos.

Zizu continua produtivo e já adaptado às normas e às exigências da empresa portanto, ainda integrado à dinâmica da excelência. Por sua vez, Armando e Francisca já não se percebem como parte da empresa nem de seu grupo de trabalho. Ambos sentem-se - como afirmou um trabalhador bancário com LER/DORT, entrevistado em outro estudo - um "meiotrabalhador", ou o equivalente a "meia força de trabalho" (Acário, 2006). Em termos racionais, ambos sabem-se capazes, mas, do ponto de vista afetivo, sentem-se inválidos.

Independentemente da gravidade e das consequências dos agravos que sofreram, todos conhecem experiências de constrangimento e de humilhação. E o que é a humilhação, se não "o sentimento de ser ofendido, menosprezado, rebaixado, inferiorizado, submetido, vexado e ultrajado pelo outro"? (Barreto, 2003, p. 188).

As experiências desses trabalhadores, entretanto, não se restringem a situações isoladas de humilhação, mas caracterizam-se, em geral, como assédio moral, uma vez que se trata de ocorrências repetidas de um conjunto de atos negativos provocados por indivíduos investidos de poder, deixando os trabalhadores em desvantagem no que diz respeito a formas de defesa (Ausfelder, 2002).

A pressão constante por uma produtividade que ultrapassa a própria capacidade ou o domínio técnico do trabalhador sobre sua tarefa; o descrédito e o descaso dos médicos, bem como dos supervisores ou gerentes, sobre as queixas dos trabalhadores; as constantes ameaças de demissão por erro ou por incapacidade de trabalho - tudo consiste em atos negativos que provocam sofrimentos intensos nos trabalhadores, quando não favorece acidentes.

Nos casos de Armando e Francisca, a dor maior deve-se à desconsideração de que já foram produtivos e à decepção por tamanho investimento físico e emocional sem qualquer retorno, agora que já não podem mais produzir do mesmo modo que antes. Sentem-se traídos pelas empresas, que não lhes ofereceram qualquer proteção depois de lhes ter exaurido a força de trabalho e subtraído o sonho de crescimento profissional, agora desfeito por causa da doença (no caso de Francisca) e do acidente, em se tratando de Armando. 
Canguilhem (1990) afirma: "A saúde é uma margem de segurança às infidelidades do meio" (p. 159). Portanto, a doença ou o transtorno seriam a restrição daquela margem para responder a essas infidelidades. Como margens de tolerância às condições de vida e trabalho, saúde e doença são dimensões do processo vital humano. Ironicamente, trabalhadores, como Armando, Zizu e Francisca, vêm sofrendo por causa do não-reconhecimento de restrições dessas margens de tolerância.

A fragilidade do corpo expressa no acidente de trabalho ou na doença - seja esta relacionada ao trabalho ou não - é interpretada pelos médicos, supervisores e gerentes como desinteresse, irresponsabilidade ou, até, preguiça. As reações dos trabalhadores, diante de representações negativas como essas, revelam-se de várias formas: raiva, revolta, decepção, tristeza e vergonha. A vergonha deve-se ao fato de não poderem compartilhar, com os que se mantêm em boa saúde, a mesma capacidade de reagir às exigências do meio de que fala Canguilhem (1990), meio que aqui identificamos como mundo de produção. Sentem-se constrangidos por serem vistos como preguiçosos, como desinteressados, como quem "não quer nada" com o trabalho.

Cabe chamar a atenção para o fato de que as fábricas em tela são oriundas do Sul do Brasil. Ambas trazem marcas culturais de sua região de origem e, provavelmente, suas gerências acreditam que, para tornar produtivos os trabalhadores de seu novo território, precisam moldálos à cultura que trazem de suas matrizes. Na base dessa crença, há o entendimento de que, ao instalarem-se no Nordeste, as empresas trazem consigo uma cultura superior, que, supostamente, poderia contribuir para o "processo civilizatório" dessa região, tida como pobre e atrasada, de trabalhadores indolentes e preguiçosos. (Haesbaert, 1999; Rigotto, 2004). As gerências das fábricas veem-se, então, na incumbência de oferecer elementos que possam modelar determinados costumes culturais dos trabalhadores. Como mostraram Rigotto (2004) e Borsoi (2005a), uma das queixas presentes entre gerentes dessas fábricas refere-se à conduta dos trabalhadores em relação aos cuidados com o próprio corpo e com o ambiente de trabalho e às dificuldades em aceitarem a rigidez dos horários das fábricas, razão pela qual buscam convencê-los da necessidade de disciplinarem o corpo e as necessidades fisiológicas para os ritmos das máquinas e os turnos de trabalho. Essa busca incessante de disciplinamento dos trabalhadores em favor das metas de produtividades abre espaço, muitas vezes, para as situações de humilhação.

Assim, o preconceito das gerências oriundas de outras regiões em relação aos trabalhadores cearenses; a baixa qualificação e a carência, na região, de opções de trabalho, o que obriga esses trabalhadores a submeterem-se a condições laborais inadequadas e a baixos salários - tudo isso pode explicar, em parte, a frequência dos casos de assédio de que se tem conhecimento nessas empresas.

Francisca, Zizu e Armando expressam certa consciência da exploração que sofrem, mas são unânimes ao julgarem que quem explora e pressiona são os chefes, os supervisores, os gerentes, ou seja, os indivíduos que representam os donos do capital.

Não questionam as condições e a natureza do trabalho, nem, sequer, o salário. Quando mostram sua revolta, ela se revela como raiva, amargura, mas sempre como resposta individualizada. A solidariedade que demonstram em relação aos colegas, ou que percebem dos colegas em relação a si, não se traduz em sentimento coletivo que possa transformar-se em reivindicações, também coletivas, de mudanças na estrutura do trabalho e nas relações de mando. A consciência está centrada nas próprias experiências de dor e de sofrimento e na busca de suas formas de enfrentamento.

Isso faz sentido, pois sequer podem contar com os sindicatos de suas categorias profissionais, uma vez que tais entidades são parceiras das empresas e, de fato, não representam os interesses de seus associados. Daí que esses trabalhadores não consigam vislumbrar saídas 
políticas para as situações que enfrentam. Desse modo, o que experimentam é o desamparo e o profundo sentimento de que estão entregues à própria sorte.

\section{Referências}

Acário, S. H. da P. (2006) Reestruturação bancária, LER/DORT e suas repercussões na reabilitação. Dissertação de Mestrado, Departamento de Psicologia, Universidade Federal do Ceará, Fortaleza.

Aubert, N. (1993). A neurose profissional. In J.-F. Chanlat (Org.), O indivíduo na organização: dimensões esquecidas (vol. 2, pp. 163-193). São Paulo: Atlas.

Antunes, R. (2005). O caracol e sua concha: ensaios sobre a nova morfologia do trabalho. São Paulo: Boitempo.

Ausfelder, T. (2002). Mobbing: el acoso moral en el trabalho - prevención, síntomas y soluciones. Barcelona: Oceano.

Barreto, M. (2003). Violência, saúde e trabalho: uma jornada de humilhações. São Paulo: Educ.

Bjorkvist, K. (2001). Social defeat as a stressor in humans. Psychology Ë Behavior, 73, 435-442.

Borsoi, I. C. F. (2005a). O modo de vida dos novos operários: quando purgatório se torna paraíso. Fortaleza: UFC.

Borsoi, I. C. F. (2005b). Acidente de trabalho, morte e fatalismo. Psicologia ES Sociedade, 17 (1), 17-18.

Canguilhem, G. (1990). O normal e o patológico. Rio de Janeiro: Forense Universitária.

Dejours, C. (1999) A banalização da injustiça social. Rio de Janeiro: FGV.

Einarsen, S. (2005).The nature, causes and consequences of bullying at work: the Norwegian experience. Pistes, 7 (3).

Francischini, A. S. N. \& Azevedo, P. F.(2003). Estratégias das empresas do setor calçadista diante do novo ambiente competitivo: análise de três casos. Gestão e Produção, 10 (3), 251-265.

Hansen, A. M., Hogh, A., Persson, R., Karlson, B., Garde, A. H. \& Orbak, P. (2006). Bullying at work, health outcomes, and physiological stress response. Journal of Psychosomatic Research, 60 (11), 63-72.

Haesbaert, R. (1997). Des-territorialização e identidade: a rede "gaúcha" no Nordeste. Niterói: EDUFF.

Hoel, H., Sparks, K. \& Cooper, C. L. (2001). The cost of violence/stress at work and the benefits of a violence/stress-free working environment. Report commissioned by the International Labour Organisation, conducted by University of Manchester Institute of Science and Technology. Artigo disponível na Internet: http://www.ilo.org/public/english/protection/safework/whpwb/econo/costs.pdf. [junho 2006]

Hoel, H., Faragher, B. \& Cooper, C. L. (2004). Bullying is detrimental to health, but all bullying behaviours are not necessarily equally damaging. British Journal of Guidance $\mathcal{E}$ Counselling, 32 (3), 367-387.

Maciel, R. H. et al. (2007). Auto-relato de situações constrangedoras no trabalho e assédio moral nos bancários: uma fotografia. Psicologia $\mathbb{E}$ Sociedade, 19 (2), 117-128.

Marx, K. (1983). O capital: crítica da economia política. (vol. 1, tomo I). São Paulo: Abril Cultural.

Matthiesen, S. B. \& Einarsen, S. (2004). Psychiatric distress and symptoms of PSTD among victims of bullying at work. British Journal of Guidance $\mathcal{E}$ Counselling, 32 (3), 335-356.

Navarro, V. L. (2006). Trabalho e trabalhadores do calçado: a indústria calçadista de Franca (SP) - das origens artesanais à reestruturação produtiva. São Paulo: Expressão Popular.

Prochnik, V. \& Une, M. Y. (2005). A migração da cadeia produtiva de calçados para a região Nordeste do Brasil. Futuro da indústria: cadeias produtivas.

Rigotto, R. M. (2004). O "progresso" chegou. E agora? Tramas da (in)sustentabilidade e a sustentação simbólica do desenvolvimento. Tese de Doutorado, Departamento de Ciências Sociais, Universidade Federal do Ceará, Fortaleza.

Rigotto, R. M. (Org.). (2007) Violência e trabalho: acidentes de trabalho e humilhação na indústria calçadista do Ceará. Relatório de Pesquisa - CNPq. Fortaleza: Universidade Federal do Ceará.

Sennett, R. (2006). A cultura do novo capitalismo. Rio de Janeiro: Record. 
Tehrani, N. (2004). Bullying: a source of chronic post-traumatic stress? British journal of Guidance $\mathcal{E}$ Counselling, 32 (3), 357-366.

Vilela, R. A. G., Iguti, A. M. \& Almeida, I. M. (2004). Culpa da vítima: um modelo para perpetuar a impunidade nos acidentes do trabalho. Cadernos de Saúde Pública, 20 (2), 570-579.

\section{Endereço para correspondência}

cristinaborsoi@uol.com.br, raquelrigotto@gmail.com, reginaheloisamaciel@gmail.com

Recebido em: 02/09/2008

Revisado em: 01/12/2008

Aprovado em: 10/12/2008 